\title{
Prevalence of common $\alpha$-thalassemia determinants in south Brazil: Importance for the diagnosis of microcytic anemia
}

Sandrine C. Wagner ${ }^{1,2}$, Simone M. de Castro ${ }^{3}$, Tatiana P. Gonzalez ${ }^{1}$, Ana P. Santin ${ }^{3}$, Leticia Filippon ${ }^{3}$, Carina F. Zaleski ${ }^{3}$, Laura A. Azevedo ${ }^{3}$, Bruna Amorin ${ }^{2}$, Sidia M. Callegari-Jacques ${ }^{1}$ and Mara H. Hutz

${ }^{1}$ Departamento de Genética, Universidade Federal do Rio Grande do Sul, Porto Alegre, RS, Brazil.

${ }^{2}$ Centro Universitário FEEVALE, Novo Hamburgo, RS, Brazil.

${ }^{3}$ Faculdade de Farmácia, Universidade Federal do Rio Grande do Sul, Porto Alegre, RS, Brazil.

\begin{abstract}
Alpha thalassemia has not been systematically investigated in Brazil. In this study, 493 unrelated individuals from the southernmost Brazilian state of Rio Grande do Sul were screened for deletional forms of $\alpha$-thalassemia. One hundred and one individuals had microcytic anemia ( $\mathrm{MCV}<80 \mathrm{fL}$ ) and a normal hemoglobin pattern $\left(\mathrm{Hb} \mathrm{A}_{2}<3.5 \%\right.$ and $\mathrm{Hb} F<1 \%)$. The subjects were screened for $-\alpha^{3.7},-\alpha^{4.2},-\alpha^{20.5},{ }^{\text {SEA }}$ and $-{ }^{\text {MED }}$ deletions but only the $-\alpha^{3.7}$ allele was detected. The $-\alpha^{3.7}$ allele frequency in Brazilians of European and African ancestry was 0.02 and 0.12 , respectively, whereas in individuals with microcytosis the frequency was 0.20 . The prevalence of $\alpha$-thalassemia was significantly higher in individuals with microcytosis than in healthy individuals $(p=0.001)$, regardless of their ethnic origin. There were also significant differences in the hematological parameters of individuals with $-\alpha^{3.7} / \alpha \alpha,-\alpha^{3.7} /-\alpha^{3.7}$ and $\beta$-thalassemia trait compared to healthy subjects. These data suggest that $\alpha$-thalassemia is an important cause of microcytosis and mild anemia in Brazilians.
\end{abstract}

Key words: alpha-thalassemia, Brazilian population, genotype, hemoglobin, microcytosis.

Received: January 22, 2010; Accepted: June 21, 2010.

The thalassemias are a diverse group of microcytic hemolytic anemias characterized by defective synthesis of the $\alpha$ or $\beta$ globin chain that results in $\alpha$-thalassemia and $\beta$-thalassemia, respectively (Kazazian, 1990). The molecular lesions associated with $\alpha$-thalassemia can be classified as $\alpha^{+}$or $\alpha^{0}$ defects, depending on whether they partially or completely abolish $\alpha$-globin chain production, respectively (Higgs and Weatherall, 2009).

The spectrum of mutations that underlie $\alpha$-thalassemias varies considerably among different populations. This finding suggests that these mutations almost certainly arose locally and that their frequency has expanded through a combination of natural selection, founder effect and gene drift. There is strong evidence that natural selection reflects past or present exposure to malaria. Overall, the $\alpha$-thalassemias follow a similar distribution to the $\beta$-thalassemias, extending from sub-Saharan Africa through the Mediterranean region and Middle East, to the Indian sub-continent and East and South-East Asia (for a review see Higgs and Weatherall, 2009). The most common $\alpha^{+}$-thalassemia dele-

Send correspondence to M.H. Hutz. Departamento de Genética, Universidade Federal do Rio Grande do Sul, Av. Bento Gonçalves 9500, Caixa Postal 15053, 91501-970 Porto Alegre, RS, Brazil. E-mail: mara.hutz@ufrgs.br. tional alleles are $-\alpha^{3.7}$ and $-\alpha^{4.2}$. The $-\alpha^{3.7}$ allele has been observed worldwide, with higher frequencies in some African and Mediterranean populations. The $-\alpha^{4.2}$ is most common in Asian countries although it also occurs in Mediterranean populations (Flint et al., 1993). The $-\alpha^{20.5}$ and — Med alleles are also frequent among Mediterranean populations (Kattamis et al., 1996). Non-deletional $\alpha$-thalassemias are generally less frequent and have limited geographical distributions when compared to the deletional forms of the disease (Higgs and Weatherall, 2009).

The current Brazilian population was formed by successive migratory waves. Amerindians already occupied Brazilian territory when the Portuguese arrived in 1500 and colonized the country. From the $16^{\text {th }}$ to $19^{\text {th }}$ centuries Africans were brought to Brazil as slaves, with other migratory waves of Europeans occurring in the $19^{\text {th }}$ and $20^{\text {th }}$ centuries, mainly from Italy, Germany and Spain (Salzano and Bortolini, 2002). All of these migratory events have contributed to the formation of a highly admixed multiethnic population. This heterogeneity has been documented in several genetic studies using uniparental or autosomal markers that revealed a typical, non-uniform triethnic (European+African+Amerindian) pattern for the Brazilian population gene pool. Southern populations generally have lower African and higher European contributions when 
compared to other Brazilian groups (Salzano and Bortolini, 2002; Callegari-Jacques et al., 2003; Parra et al., 2003; Zembrzuski et al., 2006; Leite et al., 2008, 2009). The migration of people mainly from sub-Saharan Africa and the Mediterranean region introduced thalassemias into the present-day Brazilian population since there is no evidence for autochthonous thalassemias in Brazilian Amerindians (Zago et al., 1995).

Although several investigations have reported the prevalence of hemoglobin disorders in Brazil, $\alpha$-thalassemia in particular has not been systematically investigated. Few studies have screened Brazilians to estimate the prevalence of $\alpha$-thalassemia in the general population. Sonati et al. (1991) observed a prevalence of 21\% heterozygous $-\alpha^{3.7} / \alpha \alpha$ and $2 \%$ homozygous $-\alpha^{3.7} /-\alpha^{3.7}$ genotypes in African Brazilian blood donors from the southeast. In another survey in a highly admixed northeastern population the $-\alpha^{3.7} / \alpha \alpha$ genotype was detected in $20 \%$ of 514 newborn babies while the homozygous genotype was seen in $2.5 \%$ of the children investigated (Adorno et al., 2005). In a recent study, the frequency of the $-\alpha^{3.7} / \alpha \alpha$ genotype in a healthy admixed northern Brazilian population was 7\% (Souza et al., 2009). The present study was done to determine the prevalence of $\alpha$-thalassemia in southern Brazilians of African and European ancestry and in a sample of patients with mild anemia, microcytosis and normal iron status from the same population.

493 unrelated individuals were enrolled in this study. The largest sample consisted of 392 volunteers (191 African Brazilians and 201 Brazilians of European ancestry) recruited randomly during free routine laboratory blood determinations in the School of Pharmacy at the Federal University of Rio Grande do Sul (UFRGS); the subjects had been sent for these determinations by city health centers. The blood samples were collected in 2001 and 2002. The remaining 101 subjects were recruited from individuals referred to the Hemoglobin Center of the same School to investigate microcytosis with no iron deficiency, chronic condition or intestinal parasitic worms. This study was approved by the Ethics Committee at UFRGS, and all of the participants provided written informed consent prior to participating in the study.

The blood samples were collected in vacuum tubes with EDTA as anticoagulant. The hematological indices were obtained with an automated counter (ABX Micros 60, Horiba Group, Japan). For those subjects referred to the Center because of microcytosis (MCV $<80 \mathrm{fL}$ ), the inclusion criterion was a previous diagnosis compatible with the possible presence of $\alpha$-thalassemia based on a normal $\mathrm{Hb}$ profile evaluated by high-performance liquid chromatography (HPLC; Bio-Rad Variant-Beta-Thal Short Program) and/or isoelectric focusing (IEF; Perkin-Elmer). All of the subjects had $\mathrm{Hb} \mathrm{A}_{2}<3.5 \%$ and $\mathrm{Hb} \mathrm{F}<1 \%$. All of the pa- tients had a normal iron status and/or a clinical suspicion of $\alpha$-thalassemia (no response to iron therapy).

Genomic DNA was obtained from peripheral blood by a salting-out procedure (Lahiri and Nurnberger, 1991). The $\alpha$-globin genotypes were screened with the polymerase chain reaction (PCR) in multiplex reactions as described by Tan et al. (2001) or in single reactions with the primers and protocols described by Dode et al. (1993). The genotypes were determined after electrophoresis of the amplicons in $1 \%$ agarose gels containing ethidium bromide. A $100 \mathrm{bp}$ ladder was used to score the band sizes and a known heterozygous sample was run as a positive control in all gels.

The genotypic distribution and allele frequencies were estimated by gene counting. Deviation from HardyWeinberg equilibrium was tested by the chi-square test. The genotypic and allele frequencies among groups were compared using the chi-square test or, when appropriate, Fisher's exact test. All statistical comparisons were done using the WinPEPI program (Abramson, 2004) with a value of $p<0.05$ indicating significance.

Hemoglobin $(\mathrm{Hb})$, hematocrit (Hct) and red blood cell (RBC) values were corrected for age and sex. Multivariate Analysis of Variance (MANOVA) was used to compare these adjusted variables, as well as the mean corpuscular volume (MCV), mean corpuscular hemoglobin (MCH) and mean corpuscular hemoglobin concentration (MCHC), with the corresponding values in patients with microcytic anemia (several $\alpha$-genotypes), in a previously characterized group of $124 \beta$-thalassemia trait carriers from the same population (Reichert et al., 2008) and in healthy (control) volunteers. The SNK procedure was used for subsequent pairwise multiple comparisons between groups, except for RBCs, for which Tamhanes test was used to account for heterocedasticity. These tests were done using SPSS v12.0.

The allele and genotypic frequencies for the various groups are shown in Table 1. All of the patients with microcytosis were screened for $-\alpha^{3.7},-\alpha^{4.2},-\alpha^{20.5},{ }^{\text {SEA }}$ and _ ${ }^{\text {MED }}$ deletions but only the $-\alpha^{3.7}$ allele was detected. Since this allele was the only one observed in microcytic patients, the investigation in volunteers was also restricted to the $-\alpha^{3.7}$ deletion. Among 201 Euro-descendents, 9 (4.5\%) were heterozygous for $-\alpha^{3.7} / \alpha \alpha$, whereas $44(23.1 \%)$ of 191 African Brazilians had $\alpha$-thalassemia: 41 (21.5\%) were heterozygous $\left(-\alpha^{3.7} / \alpha \alpha\right)$ and $3(1.6 \%)$ were homozygous $\left(-\alpha^{3.7} /-\alpha^{3.7}\right)$ for the $-\alpha^{3.7}$ deletion genotype. Among 101 subjects with mild anemia and microcytosis, 32 (31.7\%) had $\alpha$-thalassemia, of which 23 (22.8\%) were heterozygous for the $-\alpha^{3.7}$ deletion and $9(8.9 \%)$ were homozygous $\left(-\alpha^{3.7} /-\alpha^{3.7}\right)$. The $-\alpha^{3.7}$ allele frequency observed was 0.02 , 0.12 and 0.20 for Euro and African Brazilians and patients with microcytic anemia, respectively. The frequency of $\alpha$-thalassemia in patients with microcytic anemia was sig- 
Table $1-\alpha^{3.7}$ allele and genotype frequencies.

\begin{tabular}{lcccccc}
\hline & \multicolumn{2}{c}{ Allelic frequencies } & & \multicolumn{3}{c}{ Genotypes } \\
\cline { 2 - 3 } \cline { 7 - 7 } Subjects & $\mathrm{A} \alpha$ & $-\alpha^{3.7}$ & & $\alpha \alpha / \alpha \alpha$ & $-\alpha^{3.7} / \alpha \alpha$ & $-\alpha^{3.7} /-\alpha^{3.7}$ \\
\hline Euro-descendants & 0.98 & 0.02 & & $192(95.5)^{*}$ & $9(4.5)$ & 0 \\
African Brazilians & 0.88 & 0.12 & & $147(77.0)$ & $41(21.5)$ & $3(1.6)$ \\
$\mathrm{p}$ & $<0.001$ & $<0.001$ & & $<0.001$ & \\
Patients with microcytic anemia & 0.80 & 0.20 & & $69(68.3)$ & $23(22.8)$ & $9(8.9)$ \\
$\mathrm{p}^{\S}$ & $<0.001$ & $<0.001$ & & $<0.001$ & $<0.001$ & 0.027 \\
$\mathrm{p}^{\#}$ & $<0.001$ & $<0.001$ & & 0.01 & & $<0.001$ \\
\hline
\end{tabular}

*Number of individuals and percentage (in parentheses). ${ }^{\S}$ compared with Euro-descendants and African Brazilians, respectively.

nificantly higher than in healthy volunteers, regardless of their ethnic origin $(p=0.001)$.

The blood parameters in individuals with $\alpha$-thalassemia genotypes, $\beta$-thalassemia trait and volunteers are shown in Table 2. All of the volunteers had an MCV of 81.2-103.6 fL. MANOVA revealed significant differences in the hematological parameters of the various groups $\left(-\alpha^{3.7} / \alpha \alpha,-\alpha^{3.7} /-\alpha^{3.7}, \beta\right.$-thalassemia trait and volunteers) (Pillai's trace for comparison between genotypes: $\mathrm{F}=38,58 ; \mathrm{p}<0.001)$. Subsequent univariate analyses of the values for $\mathrm{Hb}, \mathrm{Hct}$ and $\mathrm{MCHC}$ clearly separated the volunteers from patients, but there was no difference among the various groups of patients. On the other hand, MCV and $\mathrm{MCH}$ discriminated among the four groups of individuals and there was a trend from high values in volunteers to low values in $\beta$-thalassemia trait patients, with intermediate values for $-\alpha^{3.7} / \alpha \alpha$ and $-\alpha^{3.7} /-\alpha^{3.7}$. Healthy volunteers and $-\alpha^{3.7} / \alpha \alpha$ subjects had similar RBC numbers $\left(4.6 \times 10^{12} / \mathrm{L}\right)$ that were significantly lower than in $\beta$-thalassemia trait carriers; individuals with $-\alpha^{3.7} /-\alpha^{3.7}$ had an intermediate number of RBCs that was not significantly different from the other groups.

Microcytic hypochromic anemia is a common hematological condition in clinical practice. As shown here, $\alpha$-thalassemia, represented by the $-\alpha^{3.7}$ deletion, is a com- mon cause of this hematological alteration (present in $31.7 \%$ of microcytic patients). These results agree with those reported by Borges et al. (2001) for a southeastern Brazilian population in which $\alpha$-thalassemia explained about $50 \%$ of the cases with microcytosis. Other studies that have used an approach similar to that described here have reported $\alpha$-thalassemia in $25 \%-80 \%$ of microcytosis patients in European or European-derived populations (Foglietta et al., 1996; Sivera et al., 1997; Bergeron et al., 2005; Di Bella et al., 2006; Lafferty et al., 2007).

This is the first report of the prevalence of $\alpha$-thalassemia in the general Brazilian population of European ancestry. The $-\alpha^{3.7}$ allele frequency observed here was 0.02 , which is similar to that observed in Portuguese (3.5\%) (Peres et al., 1995) and Italians (5\%) (Velati et al., 1986) with whom southern Brazilians of European descent share common ancestors, but was significantly $(\mathrm{p}=0.001)$ lower than in African Brazilians (Table 1). In the latter group, $\alpha$-thalassemia genotypes were present in $23.1 \%$ of the population, with an allele frequency of 0.12 . As expected in admixed populations such as the African Brazilians investigated here, this allele frequency was somewhat lower than in African populations, where the frequency of $-\alpha^{3.7} \alpha$-thalassemia ranges from $16.8 \%$ in Guinea-Bissau (Masmas et al., 2006) to $24 \%$ in Senegal (Migot-Nabias et al., 2006).

Table 2 - Blood indices in $\alpha$-thalassemia genotypes, $\beta$-thalassemia trait and healthy individuals.

\begin{tabular}{lccccc}
\hline Blood index & \multicolumn{2}{c}{ Subjects } & \multirow{2}{*}{$\mathrm{p}$} \\
\cline { 2 - 4 } & $-\alpha^{3.7} / \alpha \alpha$ & $-\alpha^{3.7} /-\alpha^{3.7}$ & $\beta$-thalassemia & Healthy & $<0.001$ \\
\hline $\mathrm{Hb}(\mathrm{g} / \mathrm{dL})^{*}$ & $11.5 \pm 0.23^{\mathrm{a}}$ & $11.3 \pm 0.16^{\mathrm{a}}$ & $11.2 \pm 0.13^{\mathrm{a}}$ & $14.1 \pm 0.12^{\mathrm{b}}$ & $<0.001$ \\
$\mathrm{RBC}(\mathrm{x} \mathrm{10} / \mathrm{L})^{*}$ & $4.65 \pm 0.12^{\mathrm{a}}$ & $5.00 \pm 0.17^{\mathrm{a}, \mathrm{b}}$ & $5.47 \pm 0.06^{\mathrm{b}}$ & $4.66 \pm 0.04^{\mathrm{a}}$ & $<0.001$ \\
$\mathrm{Hct}(\%)^{*}$ & $35.8 \pm 0.70^{\mathrm{a}}$ & $35.8 \pm 0.58^{\mathrm{a}}$ & $35.4 \pm 0.39^{\mathrm{a}}$ & $42.5 \pm 0.33^{\mathrm{b}}$ & $<0.001$ \\
$\mathrm{MCV}(\mathrm{fL})$ & $77.3 \pm 1.35^{\mathrm{a}}$ & $71.6 \pm 1.77^{\mathrm{b}}$ & $67.0 \pm 1.44^{\mathrm{c}}$ & $91.3 \pm 0.38^{\mathrm{d}}$ & $<0.001$ \\
$\mathrm{MCH}(\mathrm{pg})$ & $24.9 \pm 0.47^{\mathrm{a}}$ & $22.6 \pm 0.73^{\mathrm{b}}$ & $21.4 \pm 0.57^{\mathrm{c}}$ & $30.2 \pm 0.14^{\mathrm{d}}$ & $<0.001$ \\
$\mathrm{MCHC}(\%)$ & $31.9 \pm 0.23^{\mathrm{a}}$ & $31.6 \pm 0.35^{\mathrm{a}}$ & $31.9 \pm 0.38^{\mathrm{a}}$ & $33.1 \pm 0.76^{\mathrm{b}}$ & \\
\hline
\end{tabular}

The values are the mean \pm SEM. Hb: hemoglobin, RBC: red blood cell, Hct: hematocrit, MCV: mean corpuscular volume, MCH: mean corpuscular hemoglobin, and MCHC: mean corpuscular hemoglobin concentration. Means identified by the same letters did not differ significantly by the SNK test, except for RBC, for which the Tamhane test was used. *Analyzed using values corrected for age and sex. 
The frequency of the $-\alpha^{3.7}$ allele in this study was similar to that of three out of four Brazilian populations of African ancestry investigated by others (Sonati et al., 1991; Adorno et al., 2005), despite different degrees of African admixture, and much higher than the prevalence described in northern Brazil (7\%) where Amerindian admixture is higher than African admixture (Souza et al., 2009).

Among patients with mild anemia and microcytosis that remained undiagnosed, it is possible that the nondeletional forms of $\alpha$-thalassemia determined by the $-\alpha^{\mathrm{Hph}}$ and $-\alpha^{\mathrm{NcoI}}$ alleles, which are common in Mediterranean populations (Foglietta et al., 1996; Kattamis et al., 1996; Di Bella et al., 2006), could explain a proportion of these cases, mainly among those of European ancestry. In addition, rare deletional forms not included in the PCR multiplex reaction could also be present in some patients.

As shown in Table 2, the values for various blood parameters were significantly different among healthy volunteers and individuals with $\alpha$-thalassemia genotypes and the $\beta$-thalassemia trait. In contrast to $\beta$-thalassemia carriers, for which important regional differences in the mutational profile have been identified in Brazilian populations (Reichert et al., 2008), $\alpha$-thalassemias show considerably less variability, which greatly facilitates the implantation of adequate public health policies and diagnostic services for dealing with this frequent genetic trait and for diagnosing microcytosis. In this context, the data reported here may serve as potential reference values for the detection of Brazilian patients suspected of having thalassemia. Finally, in individuals with microcytosis that is unrelated to an iron deficiency or an inflammatory state, the identification of $\alpha$-thalassemia can avoid the need for expensive investigations to define the etiology of the anemia and eliminate unnecessary iron supplementation.

\section{Acknowledgments}

This work was supported by Conselho Nacional de Desenvolvimento Científico e Tecnológico (CNPq, Brazil), Programa de Apoio de Núcleos de Excelência (PRONEX/CNPq), Institutos do Milênio (CNPq) and Fundação de Amparo à Pesquisa do Rio Grande do Sul (FAPERGS).

\section{References}

Abramson JH (2004) WINPEPI (PEPI-for-Windows): Computer programs for epidemiologists. Epidemiol Perspect Innov $1: 6$.

Adorno EV, Couto FD, Moura Neto JP, Menezes JF, Rego M, Reis MG and Gonçalves MS (2005) Hemoglobinopathies in newborns from Salvador, Bahia, Northeast Brazil. Cad Saúde Pública 21:292-298.

Bergeron J, Weng X, Robin L, Olney HJ and Soulières D (2005) Prevalence of alpha-globin gene deletions among patients with unexplained microcytosis in a North-American population. Hemoglobin 29:51-60.
Borges E, Wenning MR, Kimura EM, Gervásio SA, Costa FF and Sonati MF (2001) High prevalence of alpha-thalassemia among individuals with microcytosis and hypochromia without anemia. Braz J Med Biol Res 34:759-762.

Callegari-Jacques SM, Grattapaglia D, Salzano FM, Salamoni SP, Crossetti SG, Ferreira ME and Hutz MH (2003) Historical genetics: Spatiotemporal analysis of the formation of the Brazilian population. Am J Hum Biol 15:824-834.

Di Bella C, Salpietro C, La Rosa M, Cuppari C, Piraino B, Cutri MR and Rigoli L (2006) Identification of alpha-thalassemia mutations in subjects from Eastern Sicily (Italy) with abnormal hematological indices and normal $\mathrm{Hb} \mathrm{A} 2$. Ann Hematol 85:829-831.

Dode C, Krishnamoorthy R, Lamb J and Rochette J (1993) Rapid analysis of -alpha 3.7 thalassaemia and alpha alpha alpha anti 3.7 triplication by enzymatic amplification analysis. $\mathrm{Br}$ J Haematol 83:105-111.

Flint J, Harding RM, Boyce AJ and Clegg JB (1993) The population genetics of the haemoglobinopathies. Baillieres Clin Haematol 6:215-262.

Foglietta E, Deidda G, Graziani B, Modiano G and Bianco I (1996) Detection of alpha-globin gene disorders by a simple PCR methodology. Haematologica 81:387-396.

Higgs DR and Weatherall DJ (2009) The alpha thalassaemias. Cell Mol Life Sci 66:1154-1162.

Kattamis AC, Camaschella C, Sivera P, Surrey S and Fortina P (1996) Human alpha-thalassemia syndromes: Detection of molecular defects. Am J Hematol 53:81-91.

Kazazian Jr HH (1990) The thalassemia syndromes: Molecular basis and prenatal diagnosis in 1990. Semin Hematol 27:209-228.

Lafferty JD, Barth DS, Sheridan BL, McFarlane AG, Halchuk LM and Crowther MA (2007) Prevalence of thalassemia in patients with microcytosis referred for hemoglobinopathy investigation in Ontario: A prospective cohort study. Am J Clin Pathol 127:192-196.

Lahiri DK, Nurnberger Jr JI (1991) A rapid non-enzymatic method for the preparation of HMW DNA from blood for RFLP studies. Nucleic Acids Res 19:5444.

Leite FP, Callegari-Jacques SM, Carvalho BA, Kommers T, Matte $\mathrm{CH}$, Raimann PE, Schwengber SP, Sortica VA, Tsuneto LT, Petzl-Erler ML et al. (2008) Y-STR analysis in Brazilian and South Amerindian populations. Am J Hum Biol 20:359-363.

Leite FP, Santos SE, Rodriguez EM, Callegari-Jacques SM, Demarchi DA, Tsuneto LT, Petzl-Erler ML, Salzano FM and Hutz MH (2009) Linkage disequilibrium patterns and genetic structure of Amerindian and non-Amerindian Brazilian populations revealed by long-range X-STR markers. Am J Phys Anthropol 139:404-412.

Masmas TN, Garly ML, Lisse IM, Rodrigues A, Petersen PT and Birgen H (2006) Inherited hemoglobin disorders in GuineaBissau, West Africa: A population study. Hemoglobin 30:355-364.

Migot-Nabias F, Pelleau S, Watier L, Guitard J, Toly C, De Araujo C, Ngom MI, Chevillard C, Gaye O and Garcia A (2006) Red blood cell polymorphisms in relation to Plasmodium falciparum asymptomatic parasite densities and morbidity in Senegal. Microbes Infect 8:2352-2358. 
Parra FC, Amado RC, Lambertucci JR, Rocha J, Antunes CM and Pena SD (2003) Color and genomic ancestry in Brazilians. Proc Natl Acad Sci USA 100:177-182.

Peres MJ, Romão L, Carreiro H, Picanço I, Batalha L, Magalhães HA, Martins MC and Lavinha J (1995) Molecular basis of alpha-thalassemia in Portugal. Hemoglobin 19:343-352.

Reichert VC, de Castro SM, Wagner SC, de Albuquerque DM, Hutz MH and Leistner-Segal S (2008) Identification of beta thalassemia mutations in South Brazilians. Ann Hematol 87:381-384.

Salzano FM and Bortolini MC (2002) The Evolution and Genetics of Latin American Populations. Cambridge University Press, Cambridge, 512 pp.

Sivera P, Roetto A, Mazza U and Camaschella C (1997) Feasibility of molecular diagnosis of alpha-thalassemia in the evaluation of microcytosis. Haematologica 82:592-593.

Sonati MF, Farah SB, Ramalho AS and Costa FF (1991) High prevalence of alpha-thalassemia in a black population of Brazil. Hemoglobin 15:309-311.

Souza AE, Cardoso GL, Takanashi SY and Guerreiro JF (2009) Alpha-thalassemia ( $3.7 \mathrm{~kb}$ deletion) in a population from the
Brazilian Amazon region: Santarém, Pará State. Genet Mol Res 8:477-481.

Tan AS, Quah TC, Low PS and Chong SS (2001) A rapid and reliable 7-deletion multiplex polymerase chain reaction assay for alpha-thalassemia. Blood 98:250-251.

Velati C, Sampietro M, Biassoni M, Cappellini MD, Wainscoat JS, Higgs DR and Fiorelli G (1986) Alpha thalassaemia in an Italian population. Br J Haematol 63:497-501.

Zago MA, Melo Santos EJ, Clegg JB, Guerreiro JF, Martinson JJ, Norwich J and Figueiredo MS (1995) Alpha-globin gene haplotypes in South American Indians. Hum Biol 67:535546.

Zembrzuski VM, Callegari-Jacques SM and Hutz MH (2006) Application of an African Ancestry Index as a genomic control approach in a Brazilian population. Ann Hum Genet $70: 822-828$.

Associate Editor: Paulo A. Otto

License information: This is an open-access article distributed under the terms of the Creative Commons Attribution License, which permits unrestricted use, distribution, and reproduction in any medium, provided the original work is properly cited. 